\title{
Effect of Design Variables, Temperature Gradiants, and Speed of Life and Reliability of a Rotating Disk
}

Erwin V. Zaretsky

Lewis Research Center

Cleveland, Ohio

Todd E. Smith and Richard August

Sverdrup Technology, Inc.

Lewis Research Center

Cleveland, Ohio

Prepared for the

2nd Thermal Engineering Conference cosponsored by the ASME and JSME Honolulu, Hawaii, March 22-27, 1987

\section{NMSA}

(NASA-TM-888B3) EFFECT OF DESIGN VARIABLES, ITMPERATURE GRADIENTS AND SEEED CF LIFE AND FELIABILITY OF \& FCTATING IISK (NASA) 26 p 


\title{
EFFECT OF DESIGN VARIABLES, TEMPERATURE GRADIENTS AND SPEED
}

\section{ON LIFE ANDRELIABLITY OF A ROTATING DISK}

\author{
Erwin V. Zaretsky* \\ National Aeronautics and Space Administration \\ Lewis Research Center \\ Cleveland, Ohio 44135
}

and

Todd E. Smith ${ }^{\star *}$ and Richard August

Sverdrup Technology, Inc.

Lewis Research Center

Cleveland, Ohio 44135

\section{SUMMARY}

A generalized methodology to predict the fatigue ilfe and reliability of a rotating disk such as used for aircraft engine turbines and compressors is advanced. The approach incorporates the computed life of elemental stress volumes to predict system life and reliabllity. Oisk speed and thermal gradients as well as design variables such as disk diameter and thickness and bolt hole size, number and location are considered.

\section{INTRODUCTION}

A key to cost effective design is the ability to accurately predict component $11 \mathrm{fe}$ without the need for extensive testing or field experience.

Current military support programs for gas turbine engines depend on life prediction methods to plan overhauls and part replacement. Errors in iffe prediction result in premature part replacement or insufficient availability of spare parts (ref. 1).

Life prediction methods for most machine elements are typically based on yield stresses and fatigue limiting stresses. However, in addition to the component's material properties, proper consideration must be given to the effects of notches, surface condition, component size, residual stress, temperature, duty cycle and environmental factors. Problems can also arise from lack of reliable fatigue data, overly-conservative design factors, inconsistencies among computer codes, and misinterpretation of the actual design loads. To compound these difficulties, the estabitshed fatigue limit for much of the reported data is a mean or average value. This can be interpreted as meaning that life is finite, even at the fatigue limiting stress (ref. 2).

In aerospace applications, an engineer must be especially cognizant of size and weight constraints which impact design decisions. While designing at or below the material fatigue limit may be desirable in most industrial applications, in aerospace applications, it is almost mandatory to design for a

\footnotetext{
*Fellow ASME.

**As AOciate Member ASME.
} 
finite life at an acceptable probability of survival. Zaretsky (ref. 2) outlined such a methodology based in part on work of $W$. Weibull (refs. 3 and 4) and G. Lundberg and A. Palmgren (refs. 5 to 7). Zaretsky's method (ref. 2) is similar in approach to that of Ioannides and Harris (ref. 8).

Mahorter, et a1. (ref. 1), discuss the accuracy of life prediction techniques for military turbine engine components such as compressor and turbine disks. The development of a $0.794 \mathrm{~mm}(0.03 \mathrm{in.})$ crack in any of the critical areas of a disk, such as bolt holes, bore, dovetail, etc., is considered the end of its low cycle fatigue (LCF) life (ref. 1). This is the life, $L_{0.1}$, at which the military requires a 99.9 percent probability of survival or a 0.1 percent fallure rate. Disk retirement policy requires that the disks be removed from service or reworked at their $L_{0.1} 1$ ife (ref. 1). The statistically predicted lives for bolt hole cracks did not agree with the analytically predicted values. These results imply that a deterministic approach to life predictions is not necessarily conservative, and that a probabilistic approach is viable in light of all the statistical variations in the design parameters.

In view of the aforementioned, it is the objective of this work to (a) apply the method of Zaretsky (ref. 2) to statistically predict the life of a generic solid disk with and without bolt holes, (b) determine the effect of disk design variables, thermal loads, and speed on relative life, and

(c) develop a generalized equation for determining disk ilfe.

\section{NOMENCLATURE}

A Material constant, stress cycles

c stress-life exponent

D disk diameter, m (in.)

E Material Young's Modulus, $\mathrm{N} / \mathrm{m}^{2}$ (psi)

e Weibull slope

$K_{D}$ proportionality constant, m (in.)

$K_{L}$ proportionality constant, $m^{2} / N\left(p s i^{-1}\right)$

$K_{N} \quad$ proportionality constant, rpm

$\mathrm{K}_{\mathrm{T}}$ proportionality constant, $K\left({ }^{\circ} \mathrm{F}\right)$

$K_{t}$ proportionality constant, $m$ (in.)

L life, stress cycles

$L_{B} \quad$ characteristic 1ife, or life at which 63.2 percent of population fail

Ls system life, stress cycles 
L10 ten percent life, life at which 90 percent of a population will survive, stress cycles

N. speed, rpm

No Dynamic Speed Capacity, rpm

$r$ radial coordinate from disk centerline, m (in.)

$R$ disk radius, in (in.)

S probability of survival

$t$ disk thickness, m (in.)

$T$ steady-state temperature, $K\left({ }^{\circ} \mathrm{F}\right)$

$v$ stress volume, $\mathrm{m}^{3}\left(\mathrm{in.}{ }^{3}\right)$

a coefficient of thermal expansion, $m / k\left(i n . /^{\circ} \mathrm{F}\right)$

ol fatigue limit stress, $N / m^{2}$ (psi)

orr radial stress component, $\mathrm{N} / \mathrm{m}^{2}$ (psi)

$\sigma_{\theta \theta}$ tangential stress component, $N / m^{2}$ (psi)

T shear stress, $\mathrm{N} / \mathrm{m}^{2}$ (psi)

$\tau_{L}$ fatigue limit stress, $N / m^{2}$ (psi)

Subscripts:

$a, b$ states $a$ and $b$, or bodies $a$ and $b$

1 th component, and denotes inner disk radius

o reference point, and denotes outer disk radius

\section{ANALYSIS}

Fallure Theory

The Weibull Weakest Link Theory (refs. 3 and 4) states that for a body, the probability of survival, $S$, is a function of at least five parameters. These five parameters are; fatigue life, L; material Weibull slope, e; stress state, $\sigma$; stress-life exponent, $c$; and stressed volume, $V$. In mathematical form this relation is expressed as:

$$
\ln \frac{1}{S} \sim{ }_{\sigma}^{C_{L}} e_{V}
$$


Successful implementation of equation (1) requires that three effects be addressed. These are:

(1) stress/1ife characteristics

(2) statistical fallure distributions

(3) stressed volume variations

A means in which the stress-life characteristic of a material can be defined is found from the stress-1ife relation general expression where,

$$
L=A \sigma^{-C}
$$

and where $A$ is a material constant. The values of $A$ and $C$ in this relation can be determined from experimental fatigue data obtained from coupon tests (ref. 9).

Rearrangement of equation (2) will allow life prediction at a certain stress state given knowledge of a reference state where the stress and cycles to fallure are known. The equation

$$
L_{b}=L_{a}\left(\frac{\sigma_{a}}{\sigma_{b}}\right)^{c}
$$

gives life $L_{b}$ at a known loading as related to state a. This equation will allow life estimation given knowledge of the stress-life exponent $c$ and a reference state a. (Note that the constant $A$ from eq. (2) is not required in eq. (3).)

The specification of material fatigue characteristics cannot be solely defined through the use of equation (3). The material data obtained for determining material values in equations (2) and (3), are usually presented as mean or median values. To account for deviations from this mean value, a Weibull distribution is used to describe the fallure distribution. The Weibull distribution indicates the statistical probability of survival of a given material or structure, under a particular loading, as a function of the number of cycles subjected to that loading. The determination of the Weibull distribution for loading conditions other than those for which test data is avallable will require knowledge of the Weibull slope and a point on the new Weibull line. The equation of a line using Welbull coordinates is:

$$
\frac{\ln S}{\ln S_{0}}=\left(\frac{L}{L_{0}}\right)^{e}
$$

for a single body at constant loading with $S_{0}$ and $L_{0}$ as known reference points.

An important implication of equation (1) is that as the volume over which a critical stress is acting is increased, a reduction in survivability will occur for the same number of cycles. Manipulation of equation 1 for two volumes subjected to equal stress gives: 


$$
s_{b}=s_{a} v_{b} / v_{a}
$$

for constant values $L, e$, and $c$. This equation shows that for two bodies of same material and subjected to identical loading, the body of larger volume will contain more probable defects and, thus, have a lower probability of surviving a flxed number of stress cycles. Equation (2) has been supported by much experimental evidence (ref. 2).

A way for predicting the life of a general body "a" related to the life of body "b" is given by:

$$
L_{b}=L_{a}\left(\frac{\sigma_{a}}{\sigma_{b}}\right)^{c}\left(\frac{v_{a}}{V_{b}}\right)^{1 / e}
$$

The derivation for equation (6) is given is appendix A. This equation is simllar in form to equation (5), but also includes the effect of differences in stressed volume.

If $n$ components combine to form a mechanical system, the system reliability relation states that:

$$
\left(\frac{1}{L_{s}}\right)^{e}=\sum_{i=1}^{n}\left(\frac{1}{L_{i}}\right)^{e}
$$

where $L_{s}$ is the total system life and $L_{i}$ is the th component's life (ref. 2). For this formulation, each component may have a different life but the survivability is constant for all the components, and hence for the system.

\section{Methodology}

The concept outlined in equation (7) can easily be extended from a mechanical system of discrete components to a continuous structure. This procedure can be used with the results of a finite element analysis, whereby a complex structure is modeled by discrete elements. Each element of the model will have a distinct volume and load-dependent stress. These elemental characteristics can be applied through equation (7) to determine the elements' lives and reliabilities and thus, the structure's life and reliability. The implementation of equation (7) to determine structural life and reliability is shown in the analysis methodology flowchart of figure 1.

The first step to fatigue 11 fe determination is to model the structure into elemental volumes and stresses. The general guidelines for finite element modeling can be used for this structure modeling. In this manner, the elemental stresses and volumes can be used directly within equations (6) and (7).

The second step in the fatigue life analys is involves selecting a critical element within the finite element model based on the maximum stress state. Because of the formulation of equations (1) to (5), all the element stresses and voiumes are normailized with respect to the critical element. 
Several different criteria can be considered for normalizing the critical structural element. These criteria are:

(1) Maximum Shear Stress Fallure Theory

(2) Maximum Normal Stress Failure Theory

(3) Maximum Element Strain Energy Density

(4) Maximum Element Volume

The maximum shear stress should generaliy be used in identifying the critical element. Justification is based on the applicability of the maximum shear stress fallure theory for ductile materials. Independent of the selected criteria, for all calculation purposes the element with maximum critical stress is given a relative iffe of unity at a probability of survival of 90 percent, or a 10-percent probability of fallure.

The normalized stresses and volumes are used to compute elemental lives relative to the critical element. The relative lives are combined using equation (7). to give a structural life relative to the critical element. Two key advantages of using this relative life methodology are:

(1) Simplified qualitative comparison between differing designs

(2) Reduced fatigue life data requirements

By normalizing a family of candidate designs through a singular critical element, qualitative assessments of designs changes on structural life can be easily and quickly made. By specifying relative lives, only one series of fatigue coupon tests need be run to establish the necessary Weibull parameters.

\section{RESULTS AND DISCUSSION}

\section{Solid disk}

Parametric analytical studies were conducted to investigate the effect of varying physical dimensions and speed on the relative lives of a generic solid disk. The physical model of the solid disk requires that the structure be divided into a series of components (elements). This is most easily done by considering the disk as a collection of concentric rings. The disk was modeled with 10 rings of equal radial increment for the parametric values of disk diameter studied. Expressions for the average hoop, radial, and maximum shear stresses occurring across the rings are derived for equations given in (ref. 10).

Assuming a stress-life exponent of 9 (refs. 8 and 9 ), the effect of Weibull slope modulus, on life was determined. The results are shown in figure 3. Weibull slopes of 1,2 , and 3.57 are equivalent to exponential, Rayleigh, and normal (Gaussian) distributions respectively (ref. 2). For Weibuli slopes of approximately 1.5 or greater, life is fairly constant. For Weibull slopes between 1 and 1.511 fe increases by approximately 15 percent. As a result, for the remainder of the analysis this effect will be considered negligible.

The effect of disk diameter on life for a speed of $9000 \mathrm{rpm}$ and a stresslife exponent, $c$, of 9 is shown in figure 4. As the disk diameter is increased, both the stress and the stress volume increase and $11 \mathrm{fe}$ will 
decrease. The effect of Weibull slope is negligible. The equation for this relation for the effect of diameter on life is

$$
\mathrm{L}_{10} \sim\left(\frac{K_{D}}{D}\right)^{20}
$$

where $D$ is the disk diameter, and $K_{D}$ is a constant equal to $0.61 \mathrm{~m}$ $(24.0$ in.).

The effect of disk thickness on the Llo life is shown in figure 5. Because the stressed volume is increased, life will decrease. The effect of Weibull slope is negligible. The equation for the relation for the effect of disk thickness on life is as follows:

$$
L_{10} \sim \frac{K_{t}}{t}
$$

where $T$ is the disk thickness, and $K_{t}$ is a constant equal to $0.0254 \mathrm{~m}$ $(1.0$ in.).

As disk speed is increased, stresses within the disk will increase. These stress increases will cause a decrease in $11 \mathrm{fe}$. The effect of disk rotational speed on Lio life is shown in figure 6 . The equation for the effect of speed on life be written as follows:

$$
\mathrm{L}_{10} \sim\left(\frac{K_{N}}{N}\right)^{14.3}
$$

where $N$ is the disk speed and $K_{N}$ is a speed constant equai to 9000 rpm.

For each stressed elemental volume within the body of the disk, the 11fe was determined using an inverse stress 11 fe relation shown in equations (2) and (3): Not all materials will exhibit the same stress-life relation. The stress -1 ife exponent is generally determined experimentally. For the previous calculations, a stress-life exponent of 9 was assumed. Using varying values of $c$ with a reference disk, the effect of the stress-1ife exponent on the Lio life of the disk was determined. These results are shown in figure 7. The equation for the effect of the stress-iife exponent on disk life is as follows:

$$
\mathrm{L}_{10} \sim\left(\frac{g}{c}\right)^{0.606}
$$

A concept first expanded by Ioannides and Harris (ref. 8) was the application of a fatigue limit in the determination of the lives of the elemental stressed volumes. Basically, the concept is that where the shearing stress is equal to or less than the value determined or assumed for the fatigue limit, the probability of survival for that elemental stressed volume is 100 percent. In their examples, Ioannides and Harris (ref. 8) use the following relation: 


$$
L_{10} \sim \frac{1}{\left(0-\sigma_{L}\right)^{c}}
$$

where $\sigma$ is the operating stress and $\sigma_{L}$ is the fatigue limiting stress at or below which no fallure is expected to occur.

The relation represented by equation (12) will result in a stress-1ife exponent inconsistent with equations (2) and (3) and was not used the analysis reported herein. Instead, equations (2) and (3) were used in determining the probability of survival and the resultant life for values of $\tau<\tau_{L}$. A 100 percent probability of survival was assumed. The results of assuming varying values of a fatigue limit for the shearing stress is shown in figure 8. An approximate relation between 11 fe and $\tau_{L}$ can be written as

$$
\mathrm{L}_{10} \sim \exp \left(K_{\mathrm{L}} \cdot \tau_{\mathrm{L}}\right)
$$

where $K_{L}$ is equal to $4.02 \times 10^{-8} \mathrm{~m}^{2} / \mathrm{N}\left(2.77 \times 10^{-4} \mathrm{psi}^{-1}\right)$.

The effect of a radial temperature difference upon the overall disk relative life was determined by considering the thermal stresses superimposed upon the centrifugal disk stresses due to disk rotation. A steady-state radial temperature distribution was applied to a disk with a very small central hole. A disk with a small central hole was considered because this configuration relieved a mathematical singularity which occurs for isothermal boundary conditions upon a solid disk. The solution of the heat diffusion equation for steady-state, one-dimensional heat transfer yields a temperature distribution as:

$$
T=\frac{\left(T_{0}-T_{1}\right)}{\ln \left(\frac{R_{0}}{R_{i}}\right)} \ln \left(\frac{r}{R_{i}}\right)+T_{1}
$$

for $T_{j}$ and $T_{0}$ the inner and outer radii temperatures. Assuming that small temperature differences exist $\left(\Delta T<500^{\circ} \mathrm{F}\right)$, an elasticity solution for the disk thermal stresses was used as:

$$
\begin{aligned}
& \sigma_{r r}=\frac{\left(T_{0}-T_{i}\right) E \alpha}{4 \ln \left(\frac{R_{0}}{R_{i}}\right)}\left[\left(\frac{R_{i}}{R_{0}}\right)^{2}-\left(\frac{R_{i}}{r}\right)^{2}+2 \ln \left(\frac{R_{0}}{r}\right)\right] \\
& \sigma_{\theta \theta}=\left[\frac{\left(T_{0}-T_{i}\right) E_{\alpha}}{4 \ln \left(\frac{R_{0}}{R_{i}}\right)}\left(\frac{R_{i}}{R_{0}}\right)^{2}-\left(\frac{R_{i}}{r}\right)+2 \ln \left(\frac{R_{0}}{r}\right)-2\right]
\end{aligned}
$$

where $T$ is the steady-state change in temperature from the initial stressfree temperature found from equation (14). The total disk stresses due to both 
the centrifugal disk loading and the thermal stresses can then be found by superposition.

This method is outlined in appendix $B$. The effect of various radial temperature differences on disk relative life is shown in figure 9. An expression for this thermal effect is as follows:

$$
\mathrm{L}_{10} \sim\left(\frac{\mathrm{K}_{\mathrm{T}}}{\Delta \mathrm{T}}\right)^{0.52}
$$

where $\Delta T$ is the radial temperature difference and $K_{T}$ is constant equal $0.56 \mathrm{~K}$ where $\Delta \mathrm{T}$ is in Kelvin or IF where $\Delta T$ is in Fahrenheit and where $\Delta T$ is equal to or greater than $K_{T}$.

By combining the product of equations (8) to (11), (13) and (17), the following equation for the 10-percent life of a uniform solid rotating disk may be obtained:

$$
L_{10} \sim\left[\left(\frac{K_{D}}{D}\right)^{20}\left(\frac{K_{t}}{T}\right)\left(\frac{K_{N}}{N}\right)^{14.3}\left(\frac{g}{c}\right)^{0.606}\left(\frac{K_{T}}{\Delta T}\right)^{0.52}\left(\exp \left(K_{T} T_{L}\right)\right)\right]
$$

Applying the concept of a material factor, $A$, which can be determined from experiment or from field experience, equation (14) can be rewritten as follows:

$$
L_{10}=A\left[\left(\frac{K_{D}}{D}\right)^{20}\left(\frac{K_{t}}{T}\right)\left(\frac{K_{N}}{N}\right)^{14.3}\left(\frac{g}{c}\right)^{0.606}\left(\frac{K_{T}}{\Delta T}\right)^{0.52}\left(\exp \left(K_{1} T_{L}\right)\right)\right.
$$

Introducing the concept of a Dynamic Speed Capacity $N_{0}$ which is defined by Zaretsky (ref. 2) as the speed which would produce a theoretical life of one milion stress cycles, then from equation (19),

$N_{0} \sim\left\{A \times 10^{-6}\left[\left(\frac{K_{D}}{D}\right)^{20}\left(\frac{K_{t}}{T}\right) K_{N}^{14.3}\left(\frac{g}{C}\right)^{0.606}\left(\frac{K_{T}}{\Delta T}\right)^{0.52}\left(\exp \left(K_{L}{ }^{T}{ }_{1}\right)\right)\right]\right\}^{1 / 14.3}$

and for any speed $N$ for a given disk geometry,

$$
L_{10} \sim\left(\frac{N_{0}}{N}\right)^{14.3}
$$

From the Weibull equations ( 3 and 4 ),

$$
\ln \ln \left(\frac{l}{S}\right)=e \ln \left(\frac{L}{L_{B}}\right)
$$

and using values of $S$ equal 0.9 and $L$ equal $L_{10}$ from equations (19) or (21), the characteristic life $L_{B}$, or the life at which 63.2 percent of the disks can be expected to fail, can be determined. Having the cha acteristic life, any life at any given probability of survival, such as the life at a 99.9 probability of survival, can be determined from equation (22). 


\section{Effect of Bolt Holes}

As discussed by Mahorter, et al, (ref. 1), failure of the disk will occur at tie-bolt holes in the disk. This will be the critical location for fallure on a disk. Using the finite element model shown in figure 2, the effect on disk life of bolt hole size, location, and number were determined. The results of this analysis are shown in figures 9 to 11 . The relative lives shown were normalized relative to the life of a solid disk with no holes having a $0.61 \mathrm{~m}$ ( 24.0 in.) diameter and being $0.0254 \mathrm{~m}$ ( 1.0 in.) thick, running at $9000 \mathrm{rpm}$ with a Weibull slope or modulus of 1.00 and a stress-life exponent, $c$, of 9 .

Figure 10 shows the effect of bolt diameter on disk fatigue 1ife. It would appear that at bolt holes having a diameter of less than $10.2 \mathrm{~mm}$ $(0.4 \mathrm{in.})$, the effect of hole size is nominal. At bolt holes larger in diameter, the effect is most significant. This analysis would suggest that the bolt holes in a disk should be smaller but more numerous in number.

The effect of increasing the number of bolt holes is shown in figure 11. Increasing the number of holes and keeping the hole diameter less than $10.2 \mathrm{~mm}$ ( 0.4 in.) appear to have less of an effect on life than having fewer holes larger in diameter. Figures 10 and 11 can be used to obtain iife modifying factors for equations (19) or (21).

Figure 12 shows the effect of hole location in the disk as a percent of the disk radius measured from the axis of rotation. The results show a general trend of increasing life as the holes are moved radially outward. This would not be unexpected since stresses decrease with increasing distance from the center. However, the trend is not totally convincing since at a location between 40 and 50 percent of the disk radius, there is an inversion of the trend, that is, life decreases and then begins to increase again. It cannot be determined with reasonable certainty that this is correct or that the finite element mesh size was properly selected for these calculations. Further analysis is required. However, it can be reasonably concluded that the bolt holes should be placed at a great distance from the center of the disk as is practical.

As discussed in the previous section, the effect of Weibull slope was considered negligible for the solid disk with no holes. However, for the disk with bolt holes, there appears to be a significant reduction in life with increases in slope. This trend was not expected. The size of the finite element mesh may have contributed to this phenomenon. However, the effect of mesh size was beyond the scope of the present investigation.

\section{SUMMARY OF RESULTS}

A method was developed to predict the fatigue life and reliability of a rotating disk such as used for aircraft engine turbines and compressors. The method incorporates the computed life at a given probability of survival of elemental stressed volumes within the body of the disk to arrive at total disk life and reliability. The effect on life of disk speed as well as design varlables such as disk diameter and thickness and bolt hole size, number and location were determined. An investigation into the effect of a radial temperature difference and the accompanying induced thermal stresses on disk relative life was also performed. In addition, material characteristics such as 
Weibull modules and fatigue limit were considered. A Dynamic Speed Capacity $N_{0}$ was introduced. The following results were obtained:

1. The life of a solid disk was inversely proportional to speed to the 14.3 power, diameter to the 20 power, thickness to the first power, and radial temperature difference to the 0.52 power.

2. For assumed material characteristics, life was inversely proportional to the stress-life exponent to the 0.606 power, and exponentially related to the fatigue limiting stress.

3. Increasing the number of bolt holes and keeping the hole diameter less than $10.2 \mathrm{~mm}$ ( $0.4 \mathrm{in.)}$ appear to have less of an effect on 1ife than having fewer holes larger in diameter.

4. As hole location is moved out radially, disk life increases suggesting placement of bolt holes at the furthest practical radial location. 


\section{APPENDIX A}

The equation for a straight line on Weibull paper is:

$$
\ln \ln \frac{1}{S_{b}}-\ln \ln \frac{1}{S_{a}}=e\left(\ln L_{b}-\ln L_{a}\right)
$$

which simplifies to:

$$
\frac{\ln S_{b}}{\ln S_{a}}=\left(\frac{L_{b}}{L_{a}}\right)^{e}
$$

This equation represents the survival probability for body "a" for any desired life at a fixed applied stress $\sigma_{a}$.

In order to develop an expression for a new load " $b$ ", estimates of the assoclated $S_{b}$ and $L_{b}$ must be made. These are:

$$
S_{b}=S_{a}
$$

and,

$$
L_{b}=L_{a}\left(\frac{\sigma_{a}}{\sigma_{b}}\right)^{c}
$$

Now, if body "b" has stress ob, but a different volume $v_{b}$.

$$
s_{b}=s_{a} v_{a} / v_{b}
$$

Using equations (A.1), (A.2), and (A.3), and equal element survivabilities, $S=S_{a}$, the reference life $L_{b}$ can be given by:

$$
\frac{L_{b}}{L_{a}}=\left(\frac{\sigma_{a}}{\sigma_{b}}\right)^{c}\left(\frac{V_{a}}{V_{b}}\right)^{1 / e}
$$


The solution of the steady heat diffusion equation in cylindrical coordinates will give a steady-state temperature distribution of [11]:

$$
T(r)=\frac{\left(T_{0}-T_{1}\right)}{\ln \left(\frac{R_{0}}{R_{1}}\right)} \ln \left(\frac{r}{R_{1}}\right)+T_{1}
$$

After isothermal boundary conditions are applied at a critical inner radius $R_{1}$, and the disk outer radius $R_{0}$. A critical inner radius is necessary to relieve a mathematical singularity at the center of a solid disk. The temperature within the inner radius was assumed constant at $T_{\mathfrak{q}}$.

An elasticity solution for the thermal stresses induced within a thin disk will require solving the following plane stress relations:

$$
\begin{gathered}
\sigma_{\theta \theta}=\alpha E\left[\frac{1}{b^{2}} \int_{r_{a}}^{r b} T(r) r d r+\frac{1}{r^{2}} \int_{r_{a}}^{r} T(r) r d r-T(r)\right] \\
\sigma_{r r}=\alpha E\left[\frac{1}{b^{2}} \int_{r_{a}}^{r} T(r) r d r+\frac{1}{r^{2}} \int_{r_{a}}^{r} T(r) r d r\right]
\end{gathered}
$$

with the steady-state temperature distribution difined in equation (B.1).

Assuming that the disk is at a uniform temperature when it is free of stress, and that $T(r)$ from equation (B.1) represents the change in temperature, $\Delta T$, substituting equation (B.1) into equations (B.2) and (B.3) gives:

$$
\sigma_{\theta \theta}=\frac{\left(T_{0}-T_{1}\right) \propto E}{4 \ln \left(\frac{R_{0}}{R_{1}}\right)}\left(\frac{R_{1}}{R_{0}}\right)^{2}-\left(\frac{R_{1}}{r}\right)^{2}+2 \ln \left(\frac{R_{0}}{r}\right)-2
$$

and

$$
\sigma_{r r}=\frac{\left(T_{0}-T_{j}\right) \propto E}{4 \ln \left(\frac{R_{0}}{R_{1}}\right)}\left(\frac{R_{1}}{R_{0}}\right)^{2}-\left(\frac{R_{1}}{r}\right)^{2}+2 \ln \left(\frac{R_{0}}{r}\right)
$$

These stress relations can be integrated across each disk element to estimate an average thermal stress acting on the element. These thermal stresses can be superimposed with the disk centrifugal stresses to determine the total element stress condition. Knowing these stresses and stressed volume, the elemental volume life can be determined. 


\section{REFERENCES}

1. Mahorter, R., London, G., Fowler, S., and Salvino, J., "Life Prediction Methodology for Aircraft Gas Turbine Engine Disks," AIAA Paper 85-1141, July 1985 .

2. Zaretsky, E.V., "Fatigue Criterion To System Design, Life and Reliability," AIAA paper 85-1140, July 1985.

3. Weibul1, W., "The Phenomenon of Rupture in Solids," Ingeniors Vetanskaps Akadamien-Handlingar. No. 153, 1939.

4. Weibu11, W., "A Statistical Distribution Function of Wide Applicability," Journal of Applied Mechanics, Vol. 18, No. 3, Sept. 1951, pp. 293-297.

5. Lundberg, G. and Palmgren, A., "Dynamic Capacity of Rolling Bearings," Ingeniors Vetanskaps Akadamien-Handlinger, No. 196, 1947.

6. Lundberg, G., and Palmgren, A., "Dynamic Capacity of Rolling Bearing," Acta Polytechnica, Mechanical Engineering Series, Vol. 1, No. 3, 1947, pp. $1-50$.

7. Lundberg, G., and Palmgren, A., "Dynamic Capacity of Rolling Bearing," Acta Polytechnica, Mechanical Engineering Series, Vol. 2, No. 4, 1952.

8. Ioannides, E., and Harris, T.A., "A New Fatigue Life Model for Rolling Bearings," Journal of Tribology, Vol. 107, No. 3, July 1985, pp. 367-378.

9. "Technical Report on Fatigue Properties - SAE J1099," SAE Information Report, SAE Handbook, Vo 1. 1, Society of Automotive Engineers, 1986, pp. 3.62-3.70.

10. Juvinal1 R.C., Engineering Considerations of Stress, Strain, and Strength, McGraw-Hil1, New York, 1967.

11. Kreith, F., Principles of Heat Transfer, 3rd ed., Harper Row, New York, 1973, pp. 84-85. 


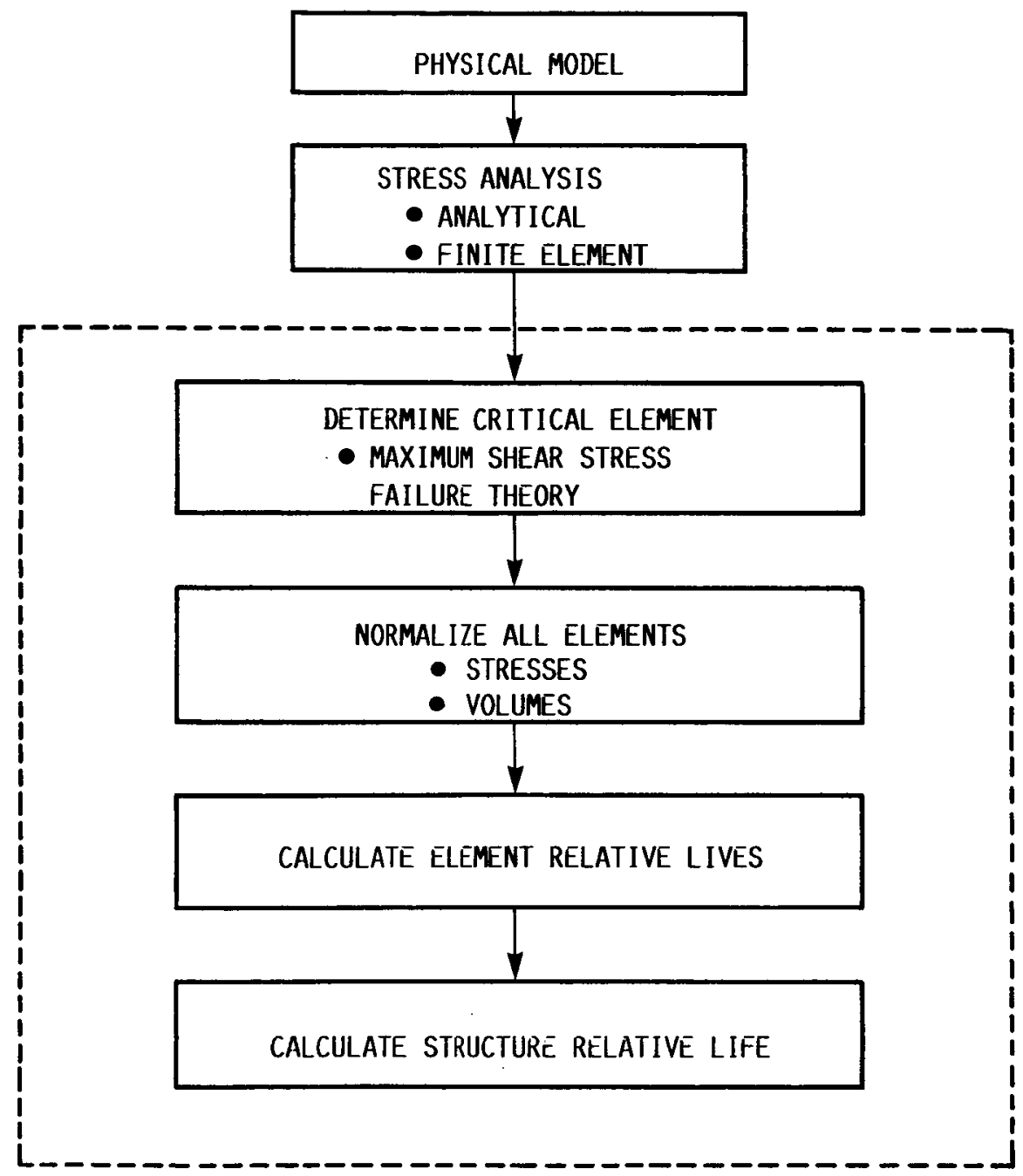

FigURE 1.- ANALYSIS METHODOLOGY FLOWCHART. 

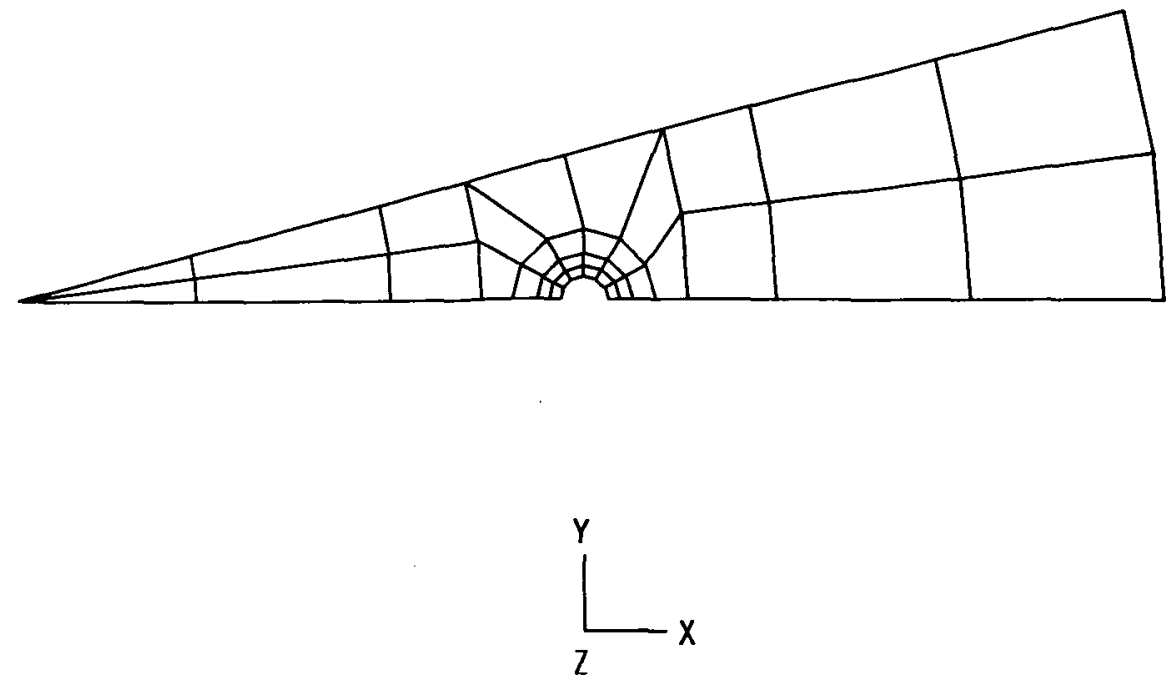

FIGURE 2.- TYPICAL FINITE ELEMENT MODEL, NOMINAL DISK CONFIGURATION: DISK DIAMETER $0.61 \mathrm{M}$ ( 24 IN.); DISK SPEED, 9000 RPM; NUMBER OF BOLT HOLES, 12 : BOLT HOLE DIAMTER, 12.7 MM $(0.5$ IN.): MATERIAL STRESSLIFE EXPONENT, C. 9 .

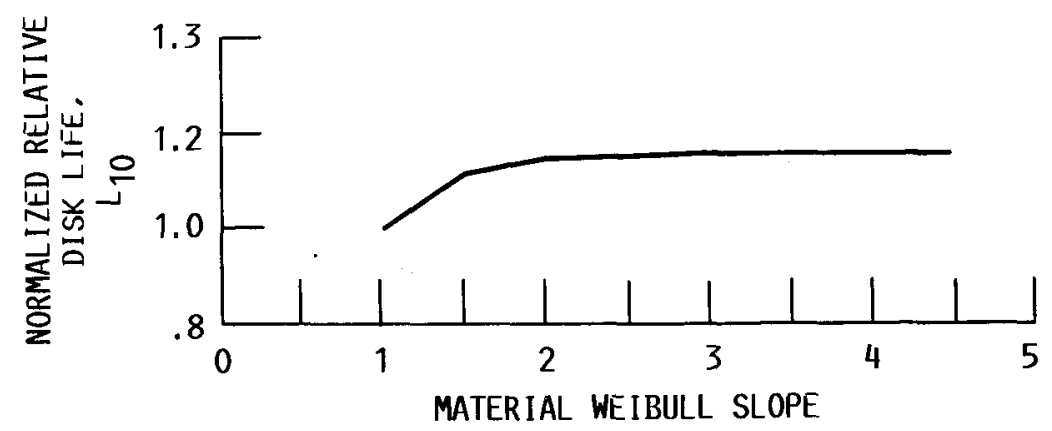

FIGURE 3. - EFFECT OF WEIBULL SLOPE ON DISK $L_{10}$ LIFE (DATA NORMALIZED TO: SLOPE $=1$, DISK DIAM $=$ 0.61 M (24.0 IN.), SPEED $=9000$ RPM, DISK THICKNESS $=0.0254 \mathrm{M}(1$ IN.). STRESS LIFE EXPONENT $=$ 9.0). 


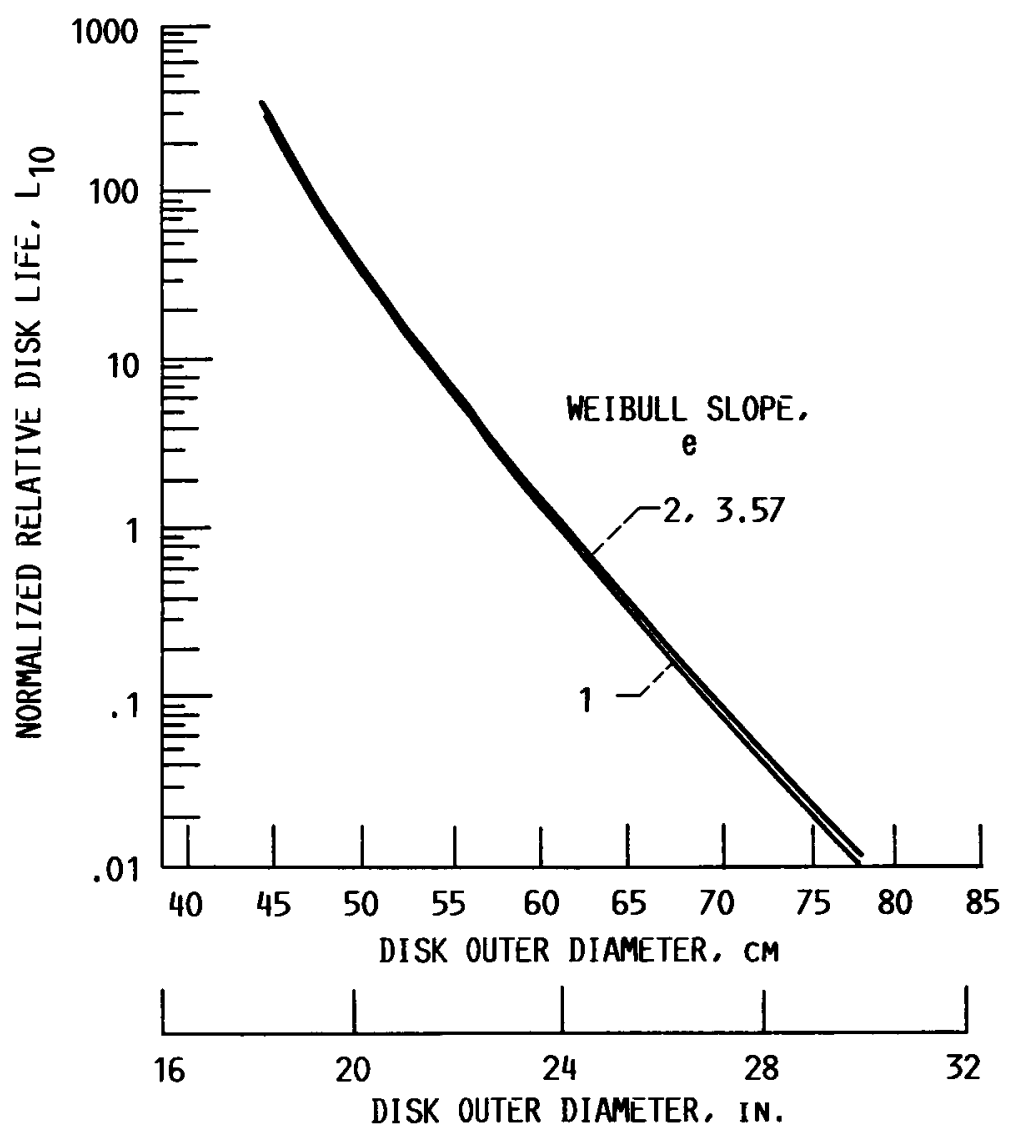

FIGURE 4.- EFFECT OF DISK DIAMETER ON DISK $L_{10}$ LIFE (DATA NORMALIZED TO: SLOPE $=1$, DISK DIAM $=0.61 \mathrm{M}(24.0 \mathrm{IN})$, SPEED $=9000 \mathrm{RPM}$, DISK THICKNESS $=0.0254 \mathrm{M}$ ( 1 IN.), STRESS LIFE EXPONENT $=9.0$ ). 


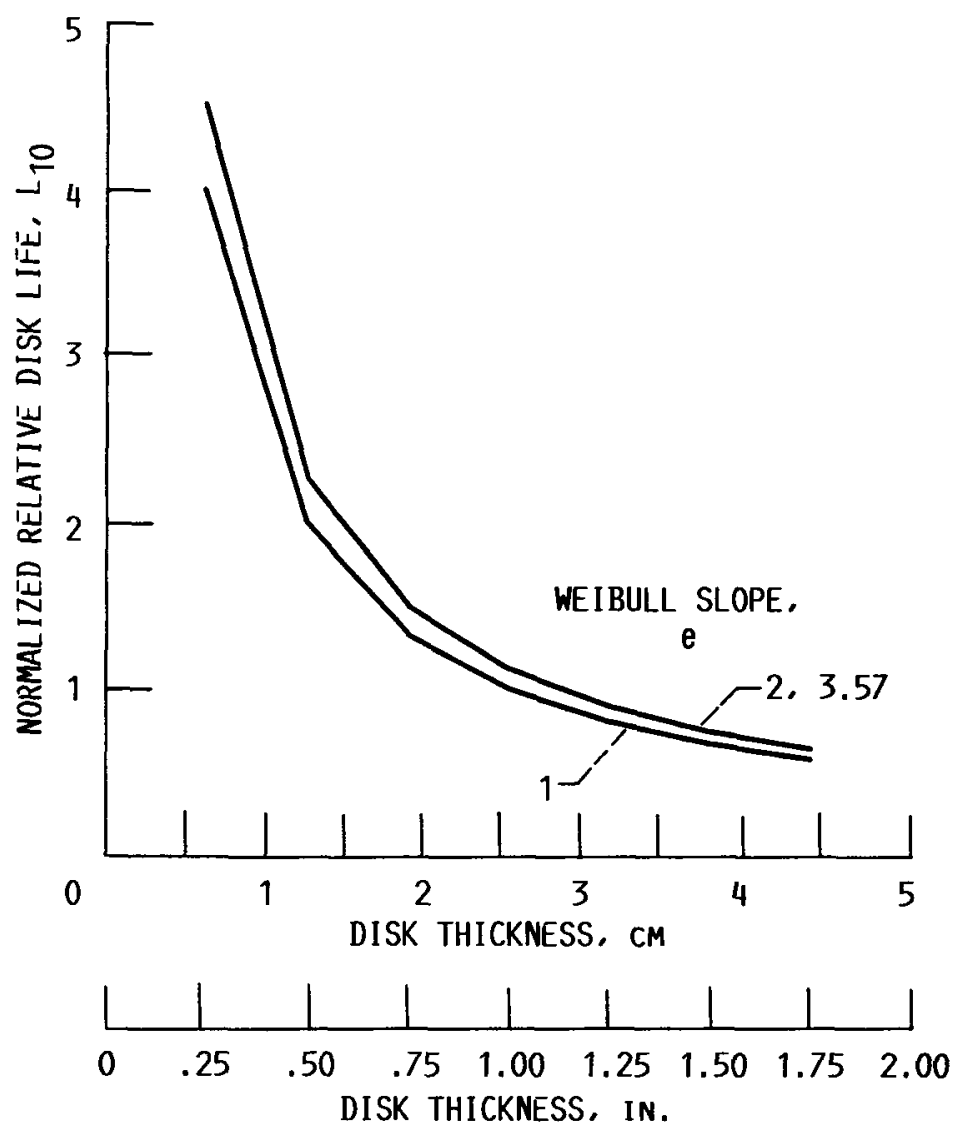

FIGURE 5.- EFFECT OF DISK THICKNESS ON DISK $\mathrm{L}_{10}$ LIFE (DATA NORMALIZED TO: SLOPE $=1$, DISK DIAM = $0.61 \mathrm{M}(24.0 \mathrm{IN}$.), SPEED $=9000 \mathrm{RPM}$, DISK THICK NESS $=0.0254 \mathrm{M}(1 \mathrm{IN}$.$) , STRESS LIFE EXPONENT =$ 9.0). 


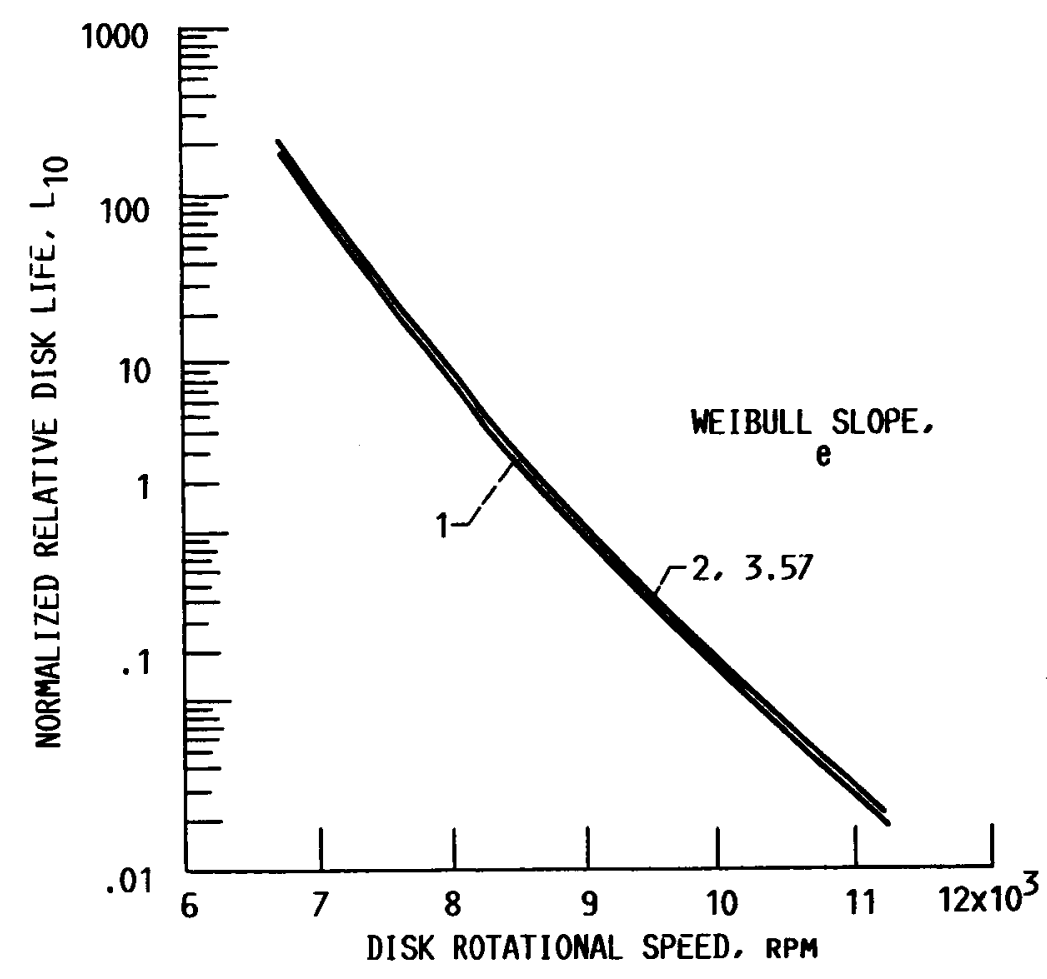

FIGURE 6. - EFFECT OF SPEED ON DISK $\mathrm{L}_{10}$ LIFE (DATA NORMALIZED TO: SLOPE $=1$, DISK DIAMETER $=0.61 \mathrm{M}(24.0 \mathrm{IN})$, SPEED $=9000 \mathrm{RPM}$, DISK THICKNESS $=0.0254 \mathrm{M}(1 \mathrm{IN}$.$) , STRESS$ LIFE EXPONENT $=9.0$ ).

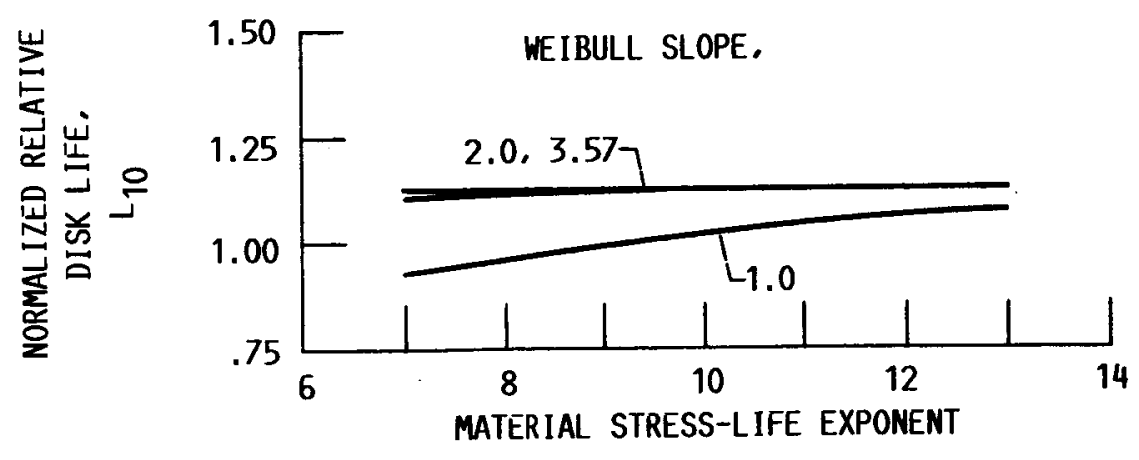

Figure 7.- EFFECT OF STRESS-LIFE EXPONENT ON DISK $L_{10}$ LIFE (DATA NORMALIZED TO: SLOPE $=1$. DISK DIAM $=0.61 \mathrm{M}(24.0 \mathrm{IN})$, SPEED $=9000 \mathrm{RPM}$. DISK THICKNESS $=0.0254 \mathrm{M}(1 \mathrm{IN}$. $)$, STRESS LIFE EXPONENT $=9.0$ ). 


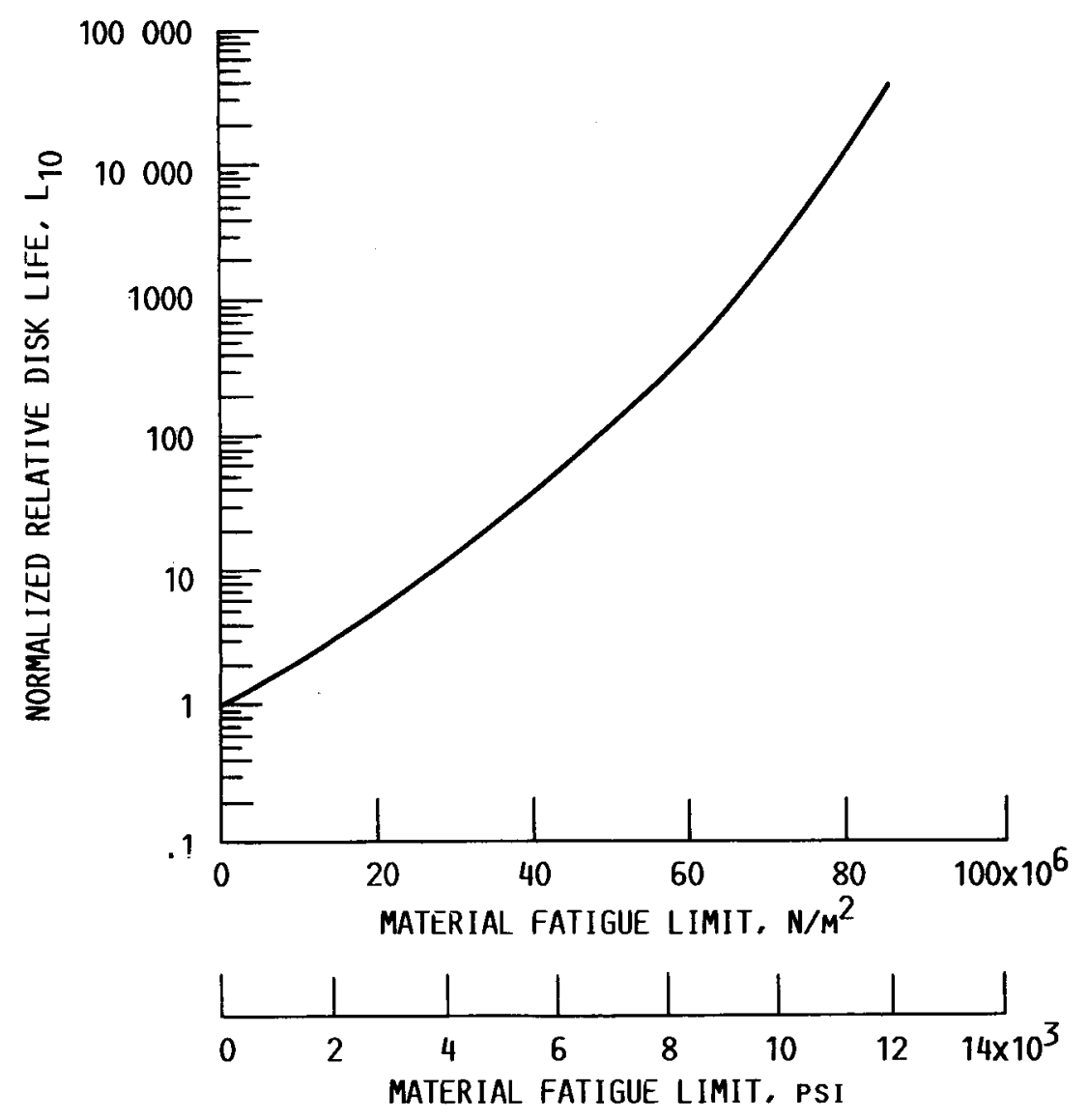

FIGURE 8. - EFFECT OF FATIGUE LIMIT ON DISK $L_{10}$ LIFE (DATA NORMALIZED TO: SLOPE $=1$, DISK DIAMETER $=0.61 \mathrm{M}(24.0 \mathrm{IN})$, SPEED $=9000 \mathrm{RPM}$, DISK THICKNESS $=0.0254 \mathrm{M}(1 \mathrm{IN}$.$) , STRESS LIFE$ EXPONENT $=9.0$ ). 


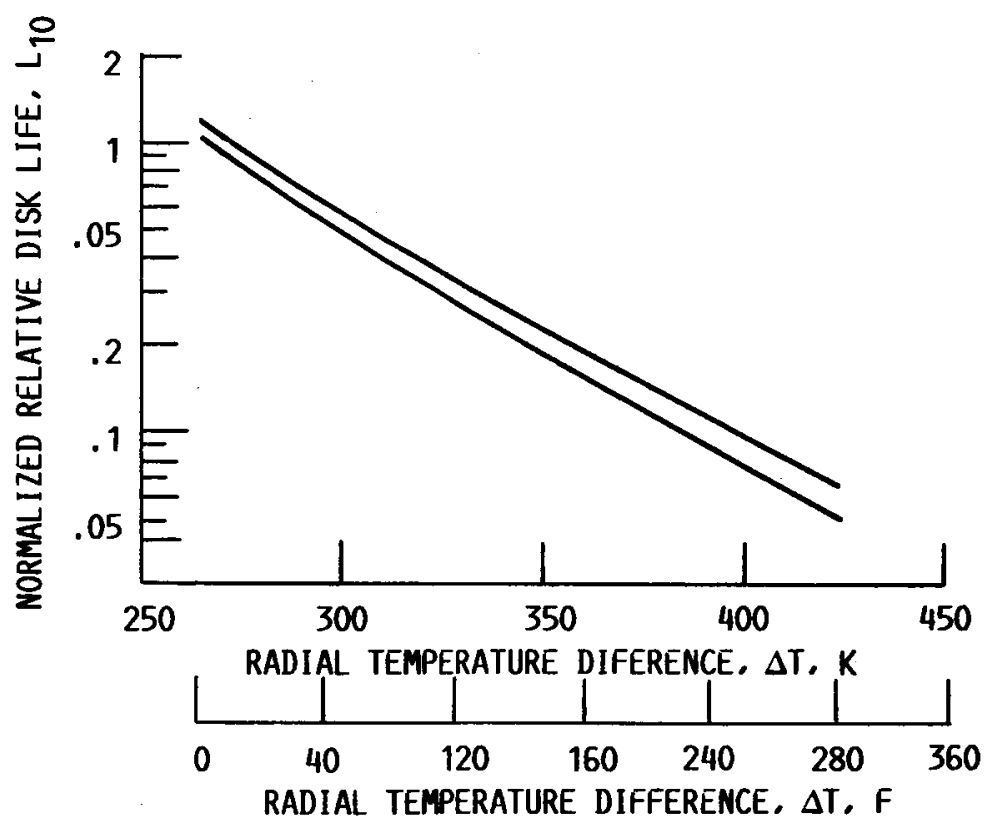

FIgURE 9.- EFFECT OF TEMPERATURE DIFFERENCE ON DISK $L_{10}$ LIFE (DATA NORMALIZED TO: SLOPE $=1$. DISK DIAMETER $=0.61 \mathrm{M}(24.0 \mathrm{IN}$.$) , SPEED =$ 9000 RPM, DISK THICKNESS $=0.0254 \mathrm{M}(1 \mathrm{IN}$.$) ,$ STRESS LIFE EXPONENT $=9.0)$. 


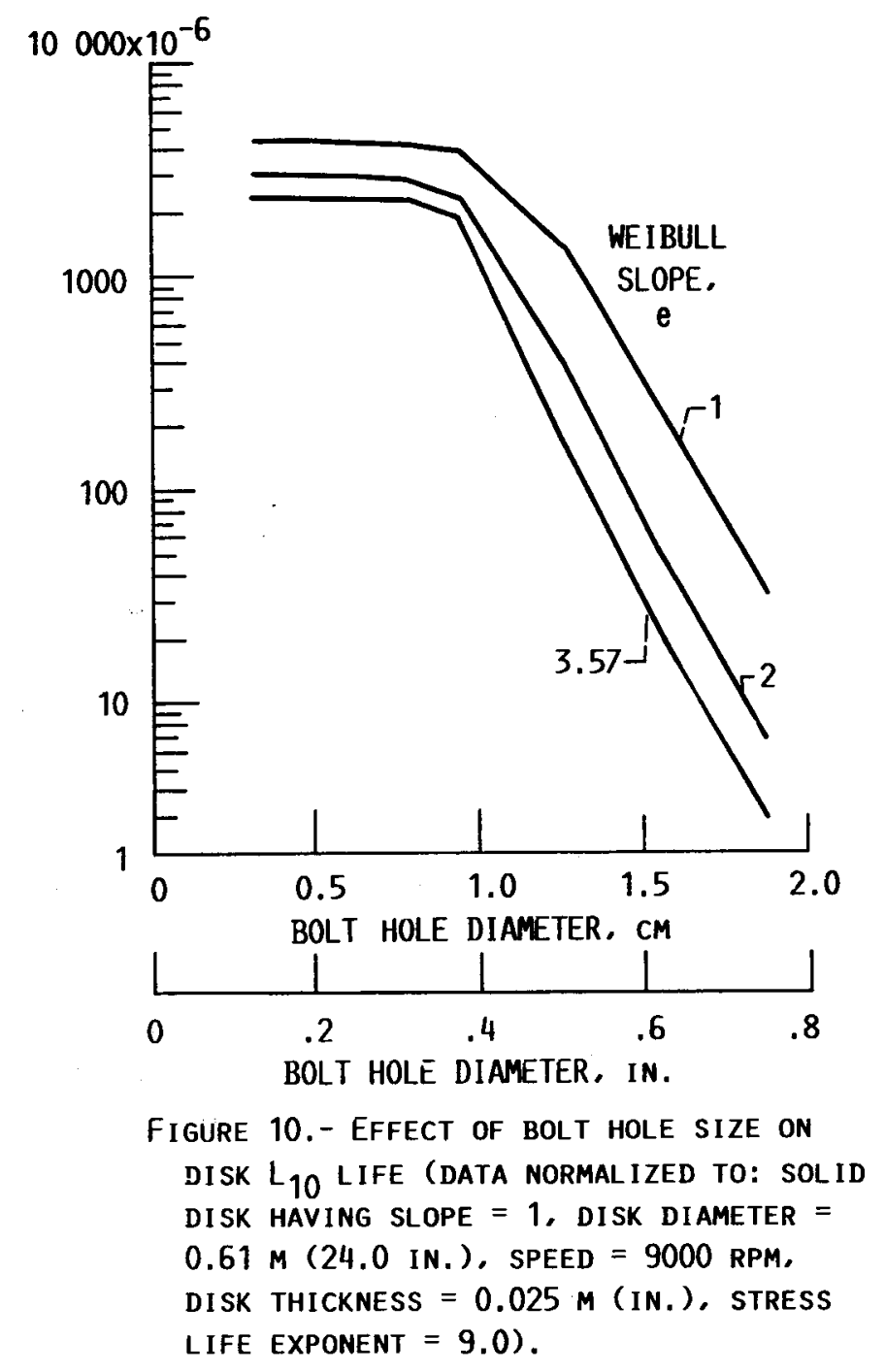




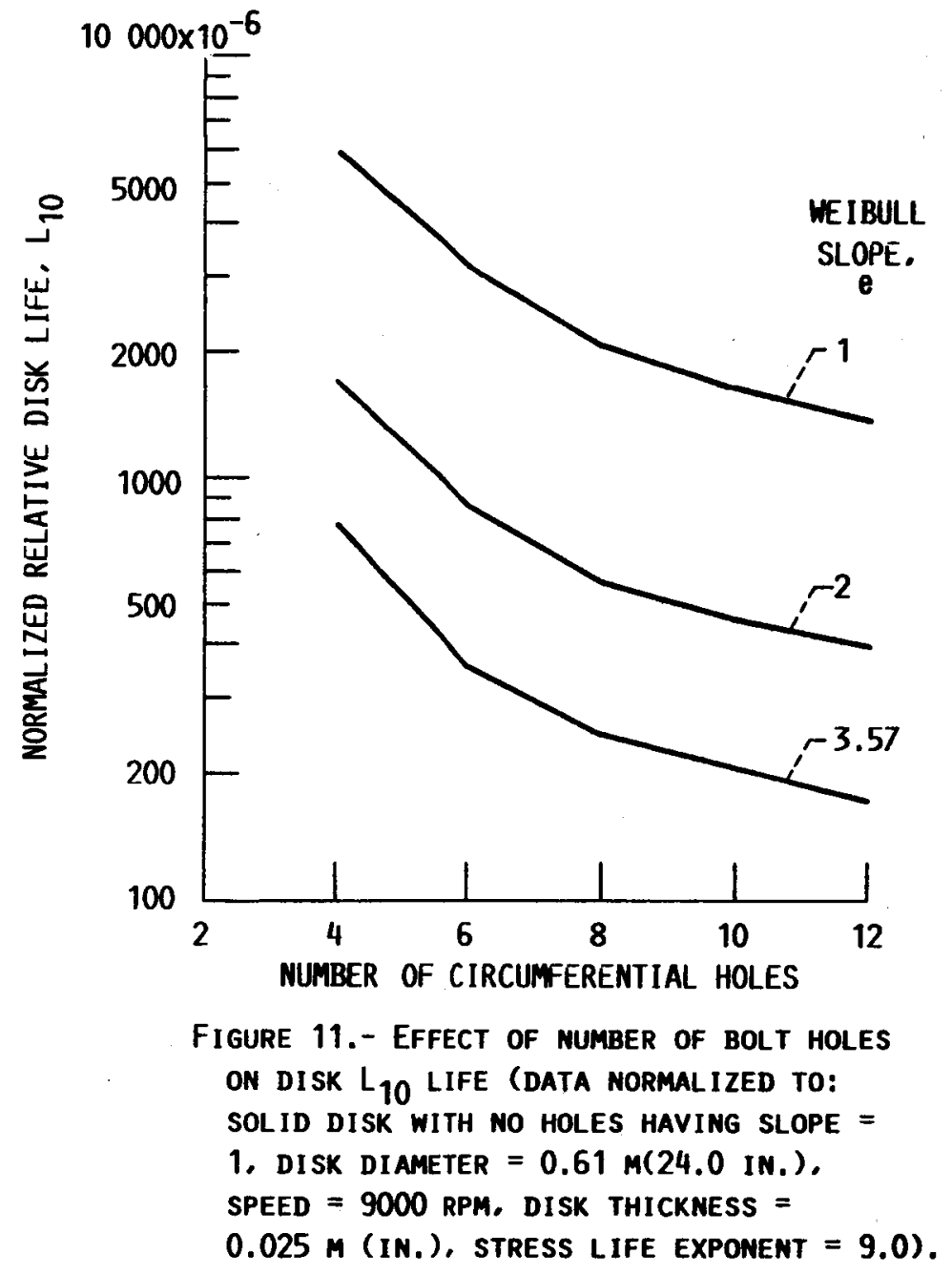




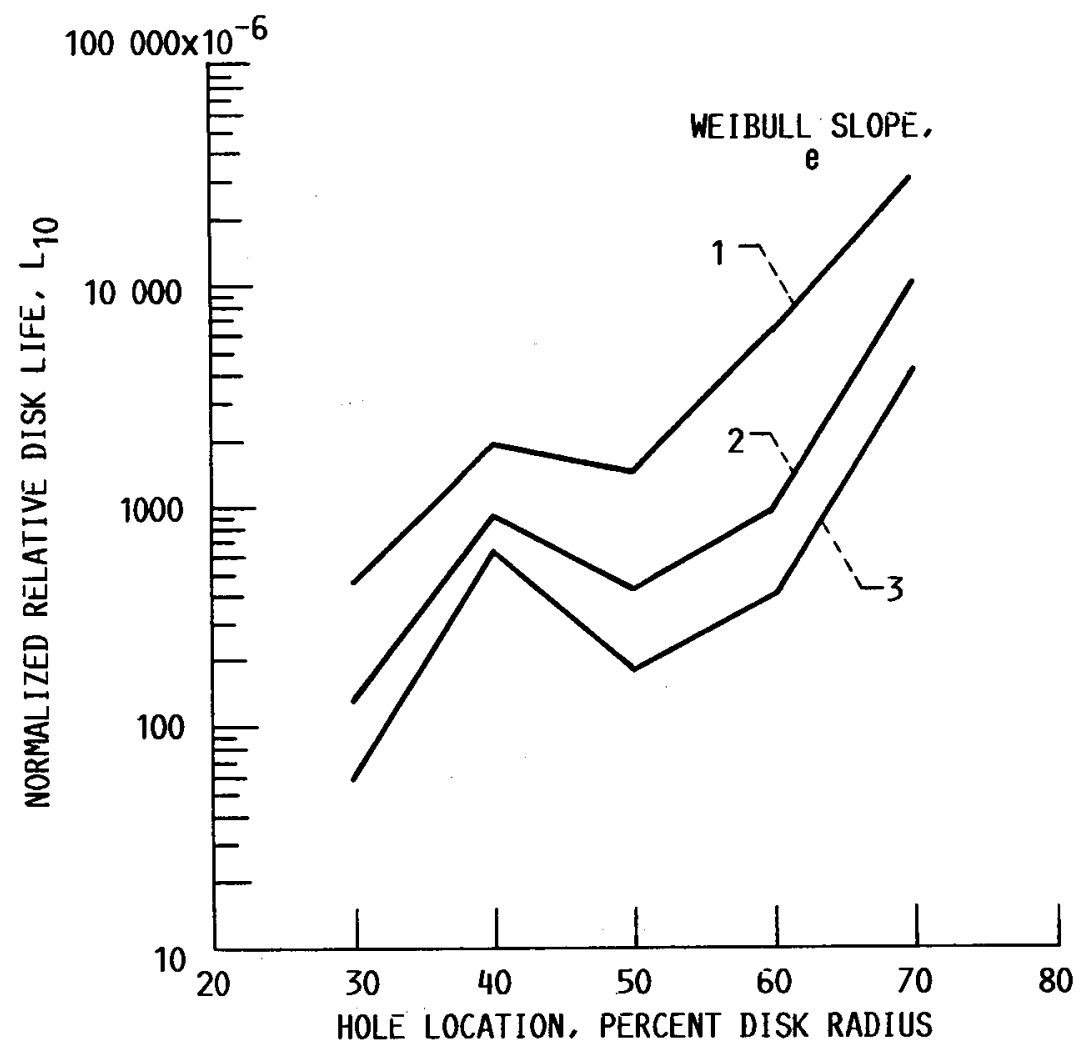

FIGURE 12. - EFFECT OF BOLT HOLE LOCATION ON DISK L10 LIFE (DATA NORMALIZED TO: SOLID DISK WITH NO HOLES HAVING SLOPE $=1$, DISK DIAMETER $=0.61 \mathrm{M}$ (24.0 IN. $),$ SPEED $=9000$ RPM, DISK THICKNESS $=$ $0.0254 \mathrm{M}(1 \mathrm{IN}$.$) , STRESS LIFE EXPONENT =9.0$ ). 


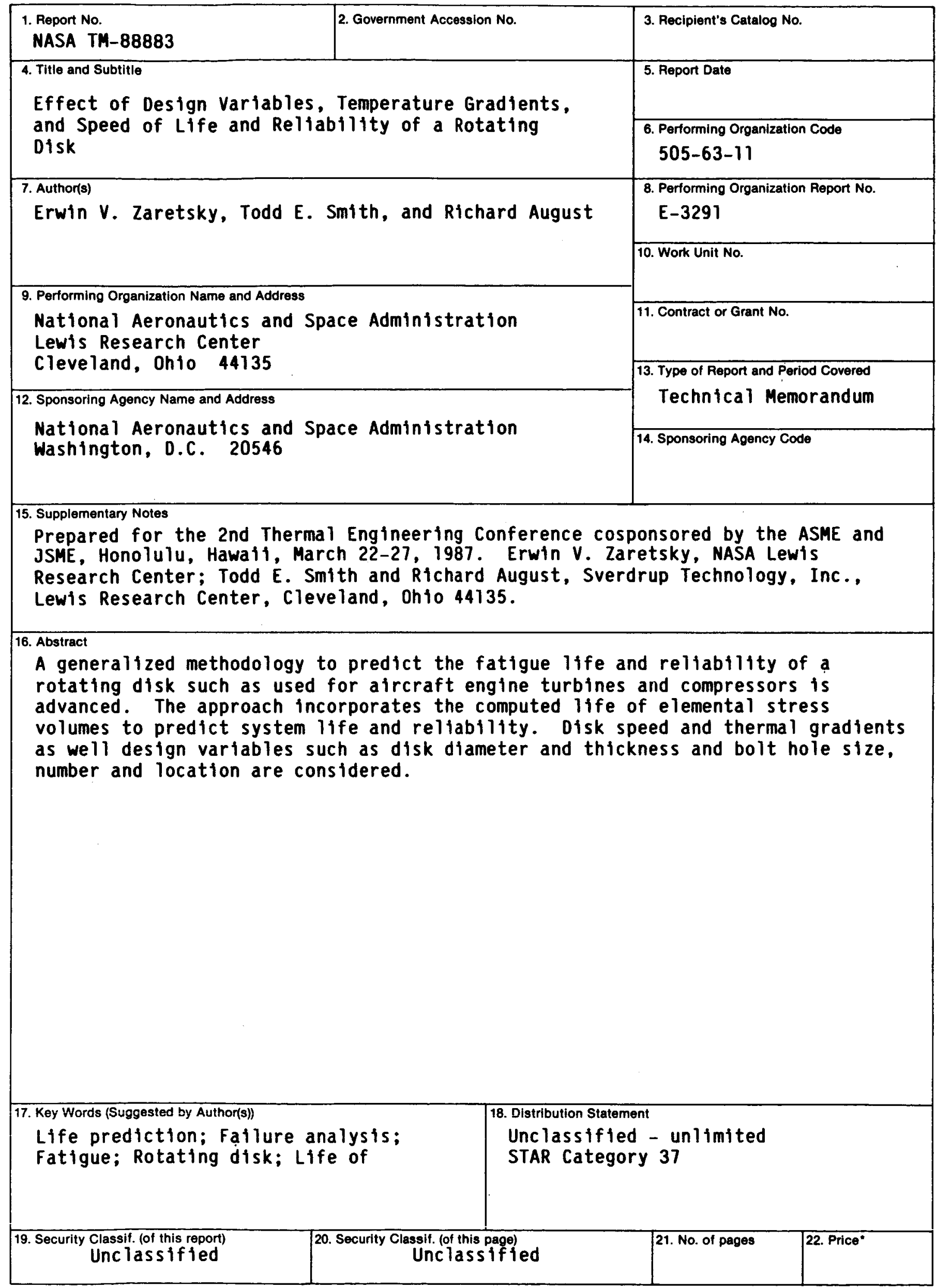

